\title{
Irunditia: as narrativas de viagem do toánucê Murillo de Campos nas expedições da comissão de Rondon ${ }^{1}$
}

\author{
Irunditia: las narrativas de viaje del toánucê a Murillo de Campos en las \\ expediciones de la comisión de Rondon
}

\section{Irunditia: the travel narratives of the toánucê Murillo de Campos in the expeditions of the commission of Rondon}

\author{
Me. Tiago Bomfim²
}

\begin{abstract}
Resumo
Este texto pretende investigar e analisar, a atuação do médico e higienista do exército brasileiro Murillo de Souza Campos, como produtor e um dos divulgadores do conhecimento científico da área da saúde desta instituição, entre os anos de 1910 a 1950. A participação de Murillo de Campos no cenário nacional foi materializada em diversas publicações como jornais, periódicos, entre outros. Para este trabalho daremos ênfase na obra "Interior do Brasil: Notas médicas e etnográficas", publicado em 1936. Neste livro Murillo de Campos descreve as viagens que realizou ao interior do Brasil no período das expedições científicas da comitiva do Candido Mariano da Silva Rondon, mais conhecido como Marechal Rondon. Nesta obra Murillo de Campos descreve suas atividades na região Nordeste de Mato Grosso, partindo do Rio de Janeiro a Cuiabá, através de Goias. Divido por regiões forjadas por este médico militar, o livro apresenta uma discussão de antropologia física e etnografia. O que nos chama atenção nesta obra e que vou explorar ao longo deste texto são as notas de tradução deste médico. Ao fim de cada capítulo Murillo de Campos apresentou um dicionário sobre os principais termos usados pelos indígenas que encontrou em sua expedição. Desta forma nossa preocupação é contextualizar este médico no campo intelectual do período e utilizando do conceito de tradução, aqui compreendo este conceito tanto no sentido da tradução como parte do processo de compreensão, por parte do receptor, da mensagem emitida por um emissor, quanto no que diz respeito às traduções de uma língua para outra. Assim sendo meu objetivo é perceber Murillo de Campos como sendo um "tradutor do mundo" que vivenciou enquanto passava pelas regiões do Brasil enquanto médico militar no início do século XX.
\end{abstract}

Palavras-Chave: Tradutor; Ciência; Murillo de Campos; Brasil.

\footnotetext{
1 Artigo apresentado no Simpósio Temático A perspectiva intercultural em estudos sobre Língua(s) de imigrantes e de fronteiras, durante o II Seminário Latino-Americano de Estudos em Cultura - SEMLACult em Foz do Iguaçu/PR, Brasil, 2018.

2 (Mestre em História e Regiões, Doutorando em História pelo Programa de Pós-Graduação em História da UNIOESTE, Marechal Cândido Rondon, Paraná, Brasil).
} 


\title{
Resumen
}

Este texto pretende investigar y analizar, la actuación del médico e higienista del ejército brasileño Murillo de Souza Campos, como productor y uno de los divulgadores del conocimiento científico del área de la salud de esta institución, entre los años 1910 a 1950. La participación de Murillo de Souza Campos en el escenario nacional se materializó en diversas publicaciones como periódicos, periódicos, entre otros. En este libro, Murillo de Campos describe los viajes que realizó al interior de Brasil en el período de las expediciones científicas de la comitiva del Candido Mariano da Silva Rondon, más conocido como Marechal Rondon. En esta obra Murillo de Campos describe sus actividades en la región Nordeste de Mato Grosso, partiendo de Río de Janeiro a Cuiabá, a través de Goias. Divido por regiones forjadas por este médico militar, el libro presenta una discusión de antropología física y etnografía. Lo que nos llama atención en esta obra y que voy a explorar a lo largo de este texto son las notas de traducción de este médico. Al final de cada capítulo Murillo de Campos presentó un diccionario sobre los principales términos usados por los indígenas que encontró en su expedición. De esta forma nuestra preocupación es contextualizar a este médico en el campo intelectual del período y utilizando el concepto de traducción, aquí comprendo este concepto tanto en el sentido de la traducción como parte del proceso de comprensión, por parte del receptor, del mensaje emitido por un emisor, que se refiere a las traducciones de una lengua a otra. Así pues, mi objetivo es percibir a Murillo de Campos como un "traductor del mundo" que vivenció mientras pasaba por las regiones de Brasil como médico militar a principios del siglo XX.

Palabras Clave: Traductor; la ciencia; Murillo de Campos; Brasil.

\begin{abstract}
This paper aims to investigate and analyze the role of the doctor and hygienist Brazilian army Murillo de Souza Campos, as a producer and one of the promoters of scientific knowledge of the health of this institution, between the years 1910 to 1950. The participation of Murillo Campos in the national scenario was materialized in several publications such as newspapers, periodicals, among others. For this work we will emphasize in the book "Inside Brazil: Medical and ethnographic notes," published in 1936. In this Campos Murillo book describes the trips he made to the interior of Brazil in the period of the scientific expeditions of the entourage of Candido Mariano da Silva Rondon, better known as Marechal Rondon. In this work Murillo de Campos describes its activities in the northeast region of Mato Grosso, departing from Rio de Janeiro to Cuiaba through Goias. Divided by regions forged by this military doctor, the book presents a discussion of physical anthropology and ethnography. What strikes us in this work and which I will explore throughout this text are the translation notes of this doctor. At the end of each chapter Murillo de Campos presented a dictionary on the main terms used by the natives he encountered on his expedition. Thus our concern is to contextualize this medical intellectually period and using the concept of translation, here
\end{abstract}


understand this concept both in the sense of translation as part of the process of understanding on the part of the receiver of the message issued by an issuer, as in which concerns translations from one language to another. So my goal is to realize Murillo de Campos as a "translator of the world" who experienced while passing through the regions of Brazil as a military doctor in the early twentieth century.

Keywords: translator; Science; Murillo de Campos; Brazil.

\section{Introdução}

No século XIX, os relatos de viagem foram um importante meio de representação do Outro e de outros países. Por meio desses interessantes e pitorescos relatos, a comunidade em geral podia formar construções imagéticas de pessoas e lugares que muitas vezes só eram possíveis de serem construídas através do olhar e leitura realizado por alguém letrado, pois dificilmente seriam visitadas pessoalmente.

Em geral, o conceito de "relato de viagem" tem como significado ser uma narrativa subjetiva, que expressa impressões pessoais sobre a experiência de uma viagem. Conforme Todorov apresenta, do ponto de vista dos leitores, o autor deste gênero literário deveria se expressar sobre civilizações distintas daquela a qual o leitor pertencia. Desta forma, era fundamental que a escrita promovesse um "sentimento de alteridade em relação aos seres e os lugares evocados" (TODOROV, 2006).

Os relatos de viagem sobre o Brasil ganharam maior visibilidade a partir da abertura dos portos em 1808. Após este advento, diversos viajantes das mais diversas localidades do mundo vieram para o Brasil e publicaram suas impressões sobre o "Novo Mundo". Os relatos sobre o Brasil, não ficaram apenas a cargo dos estrangeiros. No século XX, houve um grande investimento por parte do Estado brasileiro em conhecer seu próprio território, com isso algumas instituições (de âmbito privado e público) adentraram ao interior do país e produziram diversos materiais sobre referente a estas viagens.

Desta forma, o presente artigo busca apresentar alguns excertos de um relato de viagem sobre o interior do Brasil no início do século XX, tendo em vista analisar e apresentar possibilidades de interpretação desse tipo de fonte, a partir da identificação do lugar de fala daqueles que os escreveram e da compreensão da importância, ao se trabalhar esse tipo de documento, de compreendê-los a partir da imbricação entre política e cultura.

\section{A comissão Rondon e o ideal de ciência e nação}


$\mathrm{O}$ início do século $\mathrm{XX}$ brasileiro foi marcado por diversos empreendimentos promovido pelo governo para conhecer e explorar seu território e população. Além das expedições ao interior do Brasil promovida por Oswaldo Cruz, Carlos Chagas, RoquettePinto, entre outros pesquisadores para avaliar a condição de vida da população brasileira e conhecer os indivíduos que habitavam estas regiões, outros empreendimentos tinham o objetivo semelhante porém sob uma roupagem militar.

Um destes empreendimentos foi a "Comissão construtora de linhas telegráficas de Mato Grosso", também conhecida como “Comissão Rondon”. Sob o comando do engenheiro militar Cândido Mariano da Silva Rondon, este projeto que durou em meados dos anos de 1900 a 1930, teve dois momentos de grande marcha destes militares ao interior do Brasil que foram organizadas para a expansão da rede telegráfica nacional, fragmentada em diversos estágios, secções e expedições menores (MACIEL, 1997).

O território abrangido por estas expedições se deu no sul do Mato Grosso (1900 a 1906), no qual atravessou o noroeste do deste estado, e percorreu o extremo sudoeste do Amazonas, hoje estado conhecido como Acre (1907-1915), porém não chegando ao seu destino final previsto que foi Manaus. (MACIEL, 1999). Compreendendo este território como um espaço com grande potencialidade ao progresso, porém carente de atividade civilizadora, os engenheiros ligados a Comissão Rondon, reproduziram este discurso gestado pela intelectualidade brasileira da virada do século XIX para o XX. "Ocupar" e "avançar fronteiras" eram os principais objetivos do governo Republicano a ser conduzido pelo exército.

Com o objetivo de assegurar a comunicação da capital com os estados centrais do Brasil, a comissão Rondon também procurava demarcar os principais pontos estratégicos do país, justamente para incorporar e delimitar as fronteiras brasileiras. Embebida de valores positivista, a comissão não só realizou o propósito da construção de telégrafos, como também tornou-se representativa pelo contato que teve com as populações indígenas, no qual originou o primeiro órgão governamental de assistência aos índios, o SPI (Servição de Proteção aos Índios), que com o passar dos anos seria substituído pela FUNAI (Fundação Nacional do Índio) (BARBIO, 2011).

Neste sentido, povoar o território, construir ferrovias e telégrafos torna-se, para Rondon, as principais estratégias militares ou ferramentas de "civilização" a serem conduzidos pelo exército. Passar pelo interior do Brasil com as linhas férreas, rodoviárias e de telégrafo significava abrir caminho para a ocupação efetiva deste território, que só seria possível de se concretizar através do empenho do exército. Imbuído deste ideal científico do 
período, Rondon organizou alguns dos oficiais da comissão, para que estes realizassem pesquisas sobre os estudos e reconhecimentos que já haviam sido produzidos referente aos locais que a comissão passariam ou estabeleceriam acampamento. Os principais materiais que serviram de base para a comissão ter um prévio reconhecimento sobre os rios, territórios, indígenas, entre outros conhecimentos, foram os relatos de viajantes do século XVIII (MACIEL, 1999).

A partir deste conhecimento prévio levantado pelos oficiais da comissão, foram produzidos novos relatos destas viagens ressaltando os estudos sobre a dimensão das áreas, solos, riquezas minerais, clima, florestas e possíveis locais de povoamento. Devido a grande proporção que estas pesquisas, diversas áreas do conhecimento foram se instituindo neste período, por exemplo, a botânica, zoologia, antropologia, geologia, entre outros campos de conhecimento (BARBIO, 2011).

Com o passar dos anos, a construção das redes telegráficas, tornou-se cada vez mais sem sentido, pois o telégrafo sem fio rapidamente passou a substituir o uso destas linhas telegráficas. Com isso, os trabalhos científicos que circulavam em segundo plano, passaram a ser o foco centrar da comissão Rondon. Neste sentido, a própria figura do indígena foi uma das questões apropriada pela comissão. O objetivo de Rondon ao se apropriar das questões indígenas era de transformar o índio em trabalhador nacional (BARBIO, 2011).

Referente a esta questão, Rondon defendia que desde "pacificados" e "civilizados", estes indígenas que habitavam estas regiões seriam os melhores "guardiões das fronteiras nacionais". As pesquisas realizadas pela comissão sobre os grupos indígenas e a população sertaneja, seus modos de vida e produção, línguas e costumes, além do levantamento de dados antropométricos, buscavam construir uma representação de um "tipo ideal de raça", que sobrevive e "evolui", apesar das condições insalubres do território, porém que necessitavam apenas do contato com a civilização (MACIEL, 1999).

É nesta perspectiva que se explica a participação de profissionais em diversas áreas, principalmente do campo científico da antropologia. Conhecer e catalogar, costumes e hábitos, criar censos de habitantes, fazer registros de línguas indígenas e das expressões populares, servia para criar e estabelecer a comunicação, mas tendo em vista construir uma hierarquia entre os militares e as populações que habitavam este território.

\section{Murillo de Campos e a expedição Rondon}


O antropólogo Roquette-Pinto desenvolveu diversas pesquisas referentes a análise das culturas indígenas e dos trabalhadores que encontrou enquanto acompanhava a comissão Rondon. Ligado ao exército, Murillo de Campos foi outro cientista que buscou analisar e categorizar estas populações que habitavam o interior do Brasil.

Nascido em 18 de dezembro de 1887, em Amparo (SP), filho de João de Souza Campos e Olímpia de Souza Campos, Murillo de Campos passou grande parte de sua atuação no exército servindo em hospitais e juntas de saúde de várias regiões do Brasil. Formado em 1908 pela Faculdade de Medicina do Rio de Janeiro, defendeu a tese sobre "dores torácicas". Como "cientista militar" Murillo de Campos produziu vários livros, às suas temáticas sempre eram relacionadas às questões de higiene, doenças e também os problemas que atingiam os militares que ingressavam no serviço militar.

Dentre estas obras escritas por Murillo de Campos podemos citar os livros "Notas do interior do Brasil (Noroeste de Mato-Grosso) - Arquivos Brasileiros de Medicina” (1913); "Notas do Interior do Brasil (Do Rio de Janeiro a Cuiabá, via Goiás)", "Brasil-MédicoArquivos Brasileiros de Medicina" (1913); "Notas do Interior do Brasil (Vale do JuruenaTapajós)"; "O grupo de Esquizofrenias Ou Demência Precoce - Arquivos Brasileiros de Neurologia e Psiquiatria” (1929); "Elementos de Higiene Militar” (1929); “As Constituições em Psiquiatria” (1927); “A Epilepsia e sua significação constitucional” (1934); "Introdução a Psiquiatria Objetiva" (1960); “O índio no Brasil e o problema de seu ajustamento à comunidade nacional". 3

Apesar de discutir diversos temas, Murillo de Campos adquiriu maior visibilidade no meio intelectual a partir dos seus escritos sobre higiene militar e antropologia. Sobre a produção do campo antropológico, a obra 'Notas do Interior do Brasil' (1936) foi uma reprodução de algumas notas médicas e etnográficas, que Murillo de Campos publicou após deixar a comissão Rondon. Dividida em três partes a primeira aborda a sua passagem pela região Noroeste de Mato Grosso, onde se procedia ao levantamento da linha telegráfica em demanda de Santo Antonio do Madeira. A segunda parte é destinada a viagem que fez para realizar a inspeção do Serviço de Proteção aos Índios no Noroeste de São Paulo, Sul de Goias e Leste de Mato Grosso. Por fim, a terceira parte encerra alguns dados sobre os trabalhos de uma turma da comissão encarregada da exploração do vale do Juruena - Tapajóz (CAMPOS, 1936).

3 Informações retiradas da Academia Nacional de Medicina disponível em: http://www.anm.org.br/conteudo_view.asp?id=1781. 
Ao final de cada capítulo, Murillo de Campos reserva algumas páginas para traduzir o vocabulário dos indígenas. Procurando sempre traduzir palavras que significassem partes do corpo ou doenças, Murillo de Campos retrata os principais obstáculos para realizar tal tarefa, conforme o trecho a seguir:

Tarefa difícil é a de obtenção de vocabulários de uma tribo como a dos Nhambiquaras, que se tem conservado fora do contato dos civilizados. Não se pode contar, nem ao menos com o concurso dos interpretes indígenas. E assim nunca se tem a certeza que o índio tenha compreendido exatamente o que se lhe pergunta, nem de que a sua resposta a mais adequada. Também muito embaraçosa, porque toda pessoal, é a questão da grafia do que se tem por bem ouvido (CAMPOS, 1936, p. 55).

Apesar de encontrar dificuldade, Murillo de Campos ao passar da viagem e da narrativa dos capítulos apresentou maior variedade de palavras traduzidas, o que demonstra que o mesmo passou a receber influência da cultura que encontrava e tinha contato. Percebe-se ao analisar as palavras que Murillo de Campos traduzia em seu livro, a necessidade que o mesmo tinha em tentar apresentar ao seu leitor as representações sobre a cultura que ele via ao visitar os indígenas durante os anos que trabalhou na comissão.

\section{Considerações finais}

Murillo de Campos foi um dos trabalhadores da comissão a deixar obras que retratavam a vivência que tiveram ao explorar o interior do Brasil. A preocupação em anotar e apresentar aquilo que via, parte não somente do interesse de Rondon em fazer com que seus oficiais alavancassem a produção científica do exército, mas sim de tentar representar ao leitor as diversas culturas que encontrou ao adentrar o território brasileiro.

Neste sentido, nosso objetivo aqui é refletir se seria possível pensar Murillo de Campos como um tradutor na concepção de Iúri Lotman. Para a historiografia que trabalha com este autor, a tradução parte tanto no sentido da tradução como parte do processo de compreensão, por parte do receptor, da mensagem emitida por um emissor, quanto no que diz respeito às traduções de uma língua para outra, ou seja, o ato de comunicação (de todo modo bastante complexo e, portanto, valioso do ponto de vista cultural) deve ser analisado não como um simples deslocamento de uma mensagem, a qual permanece adequada a si mesma, da consciência do emissor à consciência do receptor, e sim como uma tradução de um texto da linguagem do meu "eu" para a linguagem do teu "tu" (VÓLKOVA, 2014).

\section{Referência bibliografica}


ARAÚJO, Carolina Pucu de. A construção visual do imaginário sobre os índios na primeira república: a experiência rondoniana. Rascunhos da História, Rio de Janeiro: PUC, 1998.

BARBIO, Luciana Alves. Comissão Rondon e a representação da identidade Paresí: um diálogo através de fotografiasRECIIS - R. Eletr. de Com. Inf. Inov. Saúde. Rio de Janeiro, v5, n.2, p. 27-43, Jun., 2011

COSTA, Romana Maria Ramos. Cultura e Contato: Um estudo da sociedade Paresí no contexto das relações interétnicas. Rio de Janeiro: Museu Nacional, 1985. [Dissertação de Mestrado]

MACHADO, Maria de Fátima Roberto. Índios de Rondon: Rondon e as linhas telegráficas na visão dos sobreviventes Wáimare e Kaxíniti, grupos Paresí. Rio de Janeiro: Museu Nacional, 1994. [Tese de Doutorado]

MACIEL, Laura Antunes. A comissão Rondon e a conquista ordenada dos Sertões: espaço, telegrafo e civilização. Proj. Historia, São Paulo, mai. 1999.

SÁ, Dominichi Miranda de; SÁ, Magali Romero; LIMA, Nísia Trindade. Telégrafos e inventário do território no Brasil: as atividades científicas da Comissão Rondon (1907 1915). História, Ciências, Saúde - Manguinhos, Rio de Janeiro, v. 15, n. 3, p. 779-810, jul. set. 2008.

TODOROV, Tzvetan. “A viagem e seu relato”. In Revista de letras da UNESP. São Paulo: vol. 46, n.1, 2006.

VÓLKOVA AMÉRICO, E. O conceito de tradução na obra de Iúri Lotman: entre i

$\mathrm{n}$

$\mathrm{t}$

$\mathrm{r}$

a

d

$\mathrm{u}$

Z

i 